\title{
Discourse Markers (DMs) in Classroom Oral Presentation of Arab Postgraduate Students
}

\author{
Hussein W. Alkhawaja \\ Faculty of Modern Languages and Communication, Universiti Putra Malaysia \\ Tel: 962-79-131-9059Ｅ-mail: englishspark@gmail.com
}

\begin{abstract}
Shamala Paramasivam (Corresponding author)
Dept of English, Faculty of Modern Languages and Communication

Universiti Putra Malaysia

Tel: 60-12-235-5952Ｅ-mail: shamala@upm.edu.my
\end{abstract}

\begin{abstract}
Vahid Nimehchisalem
Dept of English, Faculty of Modern Languages and Communication

Universiti Putra Malaysia

E-mail: vahid@upm.edu.my

Zalina Mohd Kasim

Dept of English, Faculty of Modern Languages and Communication

Universiti Putra Malaysia

E-mail: zalina_mk@upm.edu.my
\end{abstract}

Received: December 27, 2021 Accepted: January 22, 2022 Published: February 10, 2022

doi:10.5296/ijl.v14i1.19391

URL: https://doi.org/10.5296/ijl.v14i1.19391

\begin{abstract}
Towards auto didacticism in the learning of English language in Malaysian universities, students are required to do oral presentations as an academic task such as presentations of articles reviews, book chapter summaries and mini or final project proposals. To conduct these
\end{abstract}


classroom oral presentations, students usually employ a number of technological aids and resources such as computers, overhead projectors and Microsoft PowerPoint software to create their slides. In fact, conducting coherent oral presentations goes beyond the use of technology to include appropriate use of linguistic devices called discourse markers. However, the absence or misuse of these markers in oral presentation would not only affect the flow of the ideas, coherence of speech and organization of facts but might also alter the intended message of the presenter. The objective of this study was to shed light on the use of these markers by focusing on the types and functions of these markers. For this purpose, a discourse analysis approach was used in which the data were collected in the form of audio-recordings of students' oral presentations, and then analyzed based on Fraser's (2009) classification and functions of discourse markers. The findings of this study are useful for instruction of better oral presentation performance of ESL/EFL learners in general and postgraduate students in particular. They also add to the current body of literature in the area of discourse studies.

Keywords: Discourse markers (DMs), Classroom oral presentations, Academic discourse, Arab postgraduate students

\section{Introduction}

With the growing emphasis on speaking skill as one aspect of language communicative competence in higher education, the importance of learning and assessing speaking has been increasingly emphasised (Galaczi, 2013; Pourfarhad, Azmey, \& Hassani, 2012). As a result, speaking in the form of oral presentation has been included as an integral component of university classroom learning and assessment. The traditional method to assess students' oral performance was for a long time made through observing students' participation and engagement in answering professors' questions or when taking part in classroom dialogues (Al Hosni, 2014; Namaziandost, Neisi, Kheryadi, \& Nasri, 2019). With the advancement of technology and the availability of equipment, especially at a university level, the learning and assessment method of speaking has been developed to include classroom oral presentations (Saputri \& Fitriati, 2019). During these presentations, students are assessed on their presentation skills, slides format as well as their language use to organize and deliver ideas in the presentations. Although classroom oral presentation has become an important method of learning speaking and an essential assessment method of speaking in modern classrooms, conducting them is a challenge for ESL/EFL learners (Alraddadi, 2019; Bianchi \& Razeq, 2017; Khan \& Salam, 2019). For Arab postgraduate students who study in Malaysian universities, conducting an oral presentation is a challenge because these students are not familiar with this teaching-learning method as it is not commonly employed in schools or universities in the Arab world (A Alghamdi, 2021). According to a number of studies that were conducted in the Arab world (Al-Hawamdeh \& Al-Khanji, 2017; Al-Sobhi \& Preece, 2018; Bianchi \& Razeq, 2017; Khan \& Salam, 2019), the teaching and learning of English in the Arab world has been to a great extent written exam-based and without much emphasis on speaking especially through oral presentations. Alamri and Al-Tunisi (2019) maintained that the educational system in the Arab countries still follow the traditional system that utilizes exam-based education and tends to ignore the importance of innovative learning techniques, such as the use of oral presentations. It is therefore important to investigate the use of oral 
presentations to shed some light on the importance of this method for students' learning and assessment process. It would also encourage these students to improve their presentation and speech skills in terms of organization, structure and language use.

Conducting effective oral presentations not only needs presentation skills or effective use of technologies, but also requires the presenter to appropriately use certain linguistic devices, called discourse markers. The use of these markers can be significantly helpful to the presenter to communicate the information and facts to the audience systematically, smoothly, effectively and persuasively so that listeners are able to better understand and follow the content of the presentations (Saputri \& Fitriati, 2019). The absence of these markers in oral presentation would not only affect the flow of the ideas, coherence of speech, and organization of facts but might also alter the real intention of the presenter (Alraddadi, 2019). Discourse markers have been examined in various spoken discourses such as lectures (Apraku, 2017), classrooms interactions (Fortuno, 2006; Lin, 2010; Rezaee, Aghagolzadeh, \& Birjandi, 2014), conferences (Fernández-Polo, 2014; Morell, 2015), interviews (Furkó, Kertész, \& Abuczki, 2019), students' everyday conversations (Hum, Trihartanti, Hum, \& Damayanti, 2014), and seminars (O'boyle, 2014). In spite of the significant and essential role of these markers in spoken discourses in general (Banguis-Bantawig, 2019) and classroom oral presentation and speaking assessment in particular (Saputri \& Fitriati, 2019), they are still under-researched and need to be given more attention.

In the case of the Arab students, using these markers can be a challenge. Moghaddasi, Bavali, and Behjat (2020) maintained that Arab students face serious problems in managing their speech in a natural and coherent way due to the transfer process from their mother tongue system. It is therefore important to analyze these markers as used by Arab students to understand how these markers function in these learners' spoken discourse in general and, more importantly, in their oral presentation.

To this end, the general objective of the present study was to find out the DMs used by Arab postgraduate students. The following research questions were asked:

1) What are the types of DMs employed by Arab postgraduate EFL students during their classroom oral presentations?

2) What are the functions of DMs as used by Arab postgraduate students during their classroom oral presentations?

\section{Literature Review}

Research on the use of DMs such as Babanoğlu (2014), Fernández, Gates Tapia and Lu (2014) and Wei (2011) focused on how the use of these markers in various communicative situations can help language speakers and listeners construct meaningful interpretation and judge the discourse as pragmatically coherent. However, there is disagreement among the researchers from different perspectives. The aspects of the disagreement involve the inability of the researchers in this area to arrive at unified final terminologies, operational definitions, and classification of these markers. Assigning the linguistic meaning and pragmatic functions achieved by these markers was also difficult as the linguistic and pragmatic functions of these 
markers were found to vary based on contextual, social, and cultural contexts (Schleef, 2009). However, there is agreement on the idea that any incorrect selection and use of these devices can lead to undesired consequences such as misunderstanding and confusion on the part of the hearer. In the following sub-sections, a review of DMs is introduced in relation to their definition, properties and classification. This is followed by reviewing past studies conducted on discourse markers.

\subsection{Definition of DMs}

Discourse markers (DMs) refer to the "lexical expressions" that are syntactically independent of the basic sentence structure and have a general core meaning (Fraser, 1988, p. 28). These markers operate at the sentence or discourse level to maintain coherence by signaling a relationship between the core meaning of the marker and the meaning of the utterance in which they exist. In this sense, these markers are relational words that help in relating what is uttered in the sentence to the meaning of the marker used in that utterance.

\subsection{Properties of DMs}

DMs not only operate at the discourse level but also at the sentence level, hence the term 'discourse' is used. They signal a semantic relationship between two neighboring sentences, thus the term 'marker' is used'. Certain connectives, such as 'so', 'because', 'and', 'but', among others, are examples of the DMs that can be used to connect sentences and create sentence coherence (Schiffrin, 1988). DMs are transactional words that serve as discourse clues or organizers to help speakers transmit their propositions and assist listeners to comprehend the speakers' propositions (Nattinger \& DeCarrico, 1992). Halliday and Hasan (1976) looked at these markers as cohesive devices that are used to organize and process the flow of segments in a text. In the same vein, Schiffrin (1987, p. 31) maintained that markers such as the conjunctions ('and', 'but', 'or', 'so', 'because') can play a relational role to connect the utterances in a given context. DMs in Schiffrin's view can create local coherence by establishing an immediate relationship between two adjacent utterances with an immediate coherent effect. Different from pragmatic markers, which can be used optionally in speech, the absences or misuse of DMs can "remove a powerful clue" needed for cohesion realization (Fraser, 1988, p. 22). Fraser gave the example of the elaborative marker 'in fact', which indicates that the next proposition after the marker is a fact, thus establishes a factual relationship between its core meaning and the proposition content that follows the marker. In example 1, the speaker uses the result marker 'so' to say that the next utterance is a result of the previous utterance. In this case, 'so' is considered a discourse marker, which operates at the discourse level to maintain coherence.

1) My father was very tired, so we sent him to hospital.

Fraser (1999, p. 944) added that the meaning of a discourse marker can be considered "procedural not conceptual" (p. 944). This means that a discourse marker can show how two segments are related to each other in a semantic relationship defined by the meaning of the marker. 'However' as a contrastive word, for example, shows that the semantic relationship between the two segments is built on contrast. 


\subsection{Fraser's (1999/2009) Approach to Classifying DMs}

Fraser (1999) maintained that discourse markers are mainly drawn from syntactic classes such as conjunctions, adverbs and prepositional phrases. These markers clarify the textual coherence relationship between the current sentence (S2) and the prior sentence (S1). They can help speakers to express their intention to relate the next turn(s) with the preceding one(s). In example 2, the speaker used the inferential marker 'so' to create a cause-effect relationship between (S1) and (S2).

2) I need to pass the exam, so I need to study hard.

Fraser (1999) categorized DMs into two main categories:

(1) Message-relating DMs:

Message-relating markers operate at the sentence level to achieve sentence coherence. They are further classified by Fraser (1999) into four subclasses.

(a) Contrastive markers: These markers signal that the explicit interpretation of S2 contrasts with an interpretation of S1. Examples of these markers are "(al)though, but, despite, however, in comparison, nevertheless, on the other hand, rather, though, whereas, yet, etc." (Fraser, 1999, p. 947). In example 3, the use of 'since' shows a contrastive relationship between S1 and S2 which is built on the speaker's assumption or belief.

3) Since the researcher used SPSS (S2), he doesn't have qualitative design (S1).

(b) Elaborative markers: Markers like "above all, also, and, besides, equally, further(more), in addition, in particular, I mean, likewise, moreover, namely, or, otherwise, similarly, too, well, what is more, etc." show elaboration by means of addition, exemplar, or similarity with different degrees (Fraser, 1999, p. 948). In example 4, the marker 'in addition' is used to show that an additional step has been taken by the researcher (S2), thus adding to the content of S1.

4) The researcher examined the subjects (S1). In addition, he conducted an interview (S2).

(c) Inferential markers: Markers like "accordingly, as a consequence/conclusion, as a result, because of, consequently, hence, it can be concluded that, of course, so, then, therefore, thus, etc." show that the content of S2 is a logical conclusion of the content or condition in S1 (Fraser, 1999, p. 948). In example 5, the selection of the framework is justified by the purpose of the study in investigating the DMs.

5) The current study seeks to explore the use of DMs (S1). Thus, the researcher used Fraser's (1999) as a framework of analysis (S2).

(d) Causal markers: Markers like 'after all', 'since', and 'because' signal that S2 provides a reason for the content presented in S1. In other words, these markers show a causal relationship between $S 1$ (result) and S2 (reason). In example 6, the speaker gives a reason in $\mathrm{S} 1$ using the discourse marker 'because' that justifies his request in S1.

6) Please hurry (S1), because we want to catch the train (S2) 
(2) Topic-relating DMs:

The topic-relating DMs operate at the discourse level to achieve discourse coherence. They help speakers to manage the discourse or set the discourse in its logical sequence (Fraser, 1999). By the use of topic-relating markers, the reference is made to the topic in the previous segment(s) not to the message implied in them. Examples of these markers are "back to my original point, before I forget, by the way, incidentally, just to update you, on a different note, speaking of $\mathrm{X}$, that reminds me, to change to topic, to return to my point, while I think of you, with regards to, after all, because, for this/that reason, since" (Fraser, 1999, p. 955). In his work, Fraser (2009, p.5), further classified topic-related markers, which he referred to as "discourse structure markers" into three sub-classes as follows:

a. Discourse Management Markers

7) 'In summary, the economy has not flourished under the Bush administration.'

8) 'I add that he will not help you until the last minute.'

b. Topic Orientation Markers: These markers serve the following functions:

- Return to a prior topic (Returning to my previous topic),

- Add to or continue with the present topic (I would like to point out that...),

- Digress from the present topic, and

- Introduce a new topic.

c. Attention Markers: These markers occur prior to orientation markers to predict for orientation. They are also used as lubricants to discourse and interaction.

9) “We must leave right away. Look, can’t you pay attention to what I'm saying."

10) "Hell will freeze over before that's likely to happen. Now, since you haven't found anyone in London to suit your taste, what about that nice West girl?” (Fraser, 2009, p. 5).

\subsection{Review of Past Studies}

Oral presentations in general and classroom oral presentations in specific have become important constituents of modern classrooms especially in a university setting (Hincks, 2010; Miima, Ondigi, \& Mavisi, 2013; Yang, Chang, Chien, Chien, \& Tseng, 2013; Young, 2008). They have replaced conventional teaching, in which the teacher is the source of information and knowledge, to become an instrument in the hand of students to be responsible for their own learning and to use language in an authentic academic setting. Although under-researched, a number of studies have been conducted to investigate this important genre.

Saputri and Fitriati (2019) analyzed the use of discourse markers by Indonesian university students during their classroom oral presentations. The focus of analysis was on determining the types and functions of these markers and their impact on students' oral fluency. By applying Belles-Fortuno's taxonomy (2006) of English discourse markers, the findings 
showed that micro markers that achieved the functions of 'addition', 'consecution', 'contrast', 'causality' and 'temporality' were the most frequently used markers. The findings revealed that students lack knowledge of the appropriate use of markers when performing oral presentations.

Elza (2020) analyzed the oral presentations of school students. The focus of research was on the students' discourse competence in conducting final project presentation. The data were analyzed following Živković (2015) model of academic oral presentation, who proposed three moves of oral presentations, namely the introduction, body, and conclusion. The findings showed that students lacked the discourse competence needed to render effective oral presentations in various aspects. First, the use of coherence markers was limited to the use of certain transition markers (eg: the first/second/third). Second, they did not structure their oral presentation properly as they did not explain the purpose of the talk, introduce the visual aids, or thank the audience. Third, the students used non-authentic expressions or phrases to relate ideas in the discourse. The study attracted attention to problematic issues that face school students in rendering effective oral presentations.

Arya (2020) investigated the use of DMs in the classroom conversation of Thai university students and other non-Thai speakers of English. The focus of investigation was on defining the frequencies of the markers and their functions in students' speech. By applying Fung and Carter's (2007) Discourse Marker Framework, the findings showed that the students used a total of 34 markers with the markers 'OK', 'but' and 'so' the most frequently used markers. These markers were found to achieve the function of participants' engagement expressed by using reference, confirming shared knowledge, hedging, reformulating, and repair markers. The findings revealed that students' production and use of DMs was deficient and inappropriate to the context due to students' lack of knowledge and awareness of using such devices.

Yulita, Rukmini and Widhiyanto (2021) compared the use of DMs between native and non-native English speakers in public speech. The focus of the study was on types of DMs used and differences in use between the two groups of speakers. By adopting Fraser's (2009) framework of discourse markers, the findings showed that the non-native speakers used 10 types of DMs: assessment, manner of speaking, evidential, hearsay, contrastive, elaborative, inferential, management, topic orientation and attention markers. The native speakers employed the same types of markers with the exception of the discourse management markers. The findings also showed that the non-native speakers used more markers than the native speakers. Both groups of the students did not use the basic pragmatic markers and non-deference markers. As for differences, the native speakers did not employ the discourse management markers. In spite of the differences between the two groups of speakers, the findings indicated the importance of these markers in public speeches.

\section{Method}

This study adopted pragmatic discourse analysis approach that employed the qualitative technique to collect data and the mixed methods technique for data analysis. 


\subsection{Subjects}

The subjects in this study consisted of 30 students ( 9 males and 21 females). These students were selected in a "homogeneous purposive sampling" method. (Creswell, 2013, p. 209). The use of this method was to select a homogeneous sample that share similar characteristics. As such, the students were Arab postgraduate students who speak Arabic as the first language and study English in the master's program offered in a Malaysian university. All the students shared the same field of study (English Applied Linguistics) and were in their second semester of study. The subjects' ages ranged from 25-31 years. The selection of only 30 students was sufficient to reach saturation point and achieve the objectives of the study.

\subsection{Data Collection}

The data in this study were collected qualitatively in the form of approximately 4-hour audio-recorded scripts obtained from 30 classroom oral presentations during the second semester of 2018 from a public university in Malaysia. Audio-recording is one of the ethnographic methods to collect natural occurring talk in the form of objective audible material (Creswell, 2012; Dörnyei, 2007). The audio-recordings were transcribed verbatim to prepare for analysis. During the presentations, the students reviewed and discussed a number of applied linguistic topics relevant to their study in the faculty.

\subsection{Data Analysis Procedures}

Following other researchers in the field of discourse studies (e.g., Ahmed \& Maros, 2017; Yakubu, 2013), four procedures were followed for the analysis of data. The first procedure was to read the data extensively to obtain familiarity with the topics being presented. The second procedure was to search the data word-by-word and sentence-by-sentence manually with more attention paid to the occurrences of the DMs. The third procedure was to ensure that the identified markers were fitting Fraser's (2009) taxonomies and criteria. For this procedure, the following inclusive criteria was applied:

(1) A discourse marker has a procedural not conceptual meaning as it relates one or more forgoing or previous segments (relational function). In other words, a discourse marker can show how the two segments it links are related to each other in a semantic relationship defined by the meaning of the marker.

(2) A discourse marker can occur in initial, middle, or final positions.

(3) A discourse marker must be part of the sentence that cannot stand alone, but needs another independent clause to complete its structure and meaning.

(4) The meaning of the discourse marker should be consistent with the meaning or message communicated in S1 and S2 (coherence function)

(5) A discourse marker does not contribute to the meaning of either segment it relates, but the absence or misuse of it can negatively affect the cohesion of the sentence.

When all markers were identified in the transcriptions, the last procedure was to apply a mixed method (quantitative and qualitative) for analysis. The quantitative analysis included 


\section{I Macrothink}

International Journal of Linguistics

ISSN 1948-5425

2022, Vol. 14, No. 1

the use of descriptive statistics (frequencies, percentages). The obtained occurrences of DMs were then interpreted qualitatively in relation to the linguistic meaning and functions achieved based on the contexts of the utterances and the oral presentation delivered.

\section{Analysis and Results}

The findings showed that the students used a total of 464 DMs in their classroom oral presentations (Figure 1).

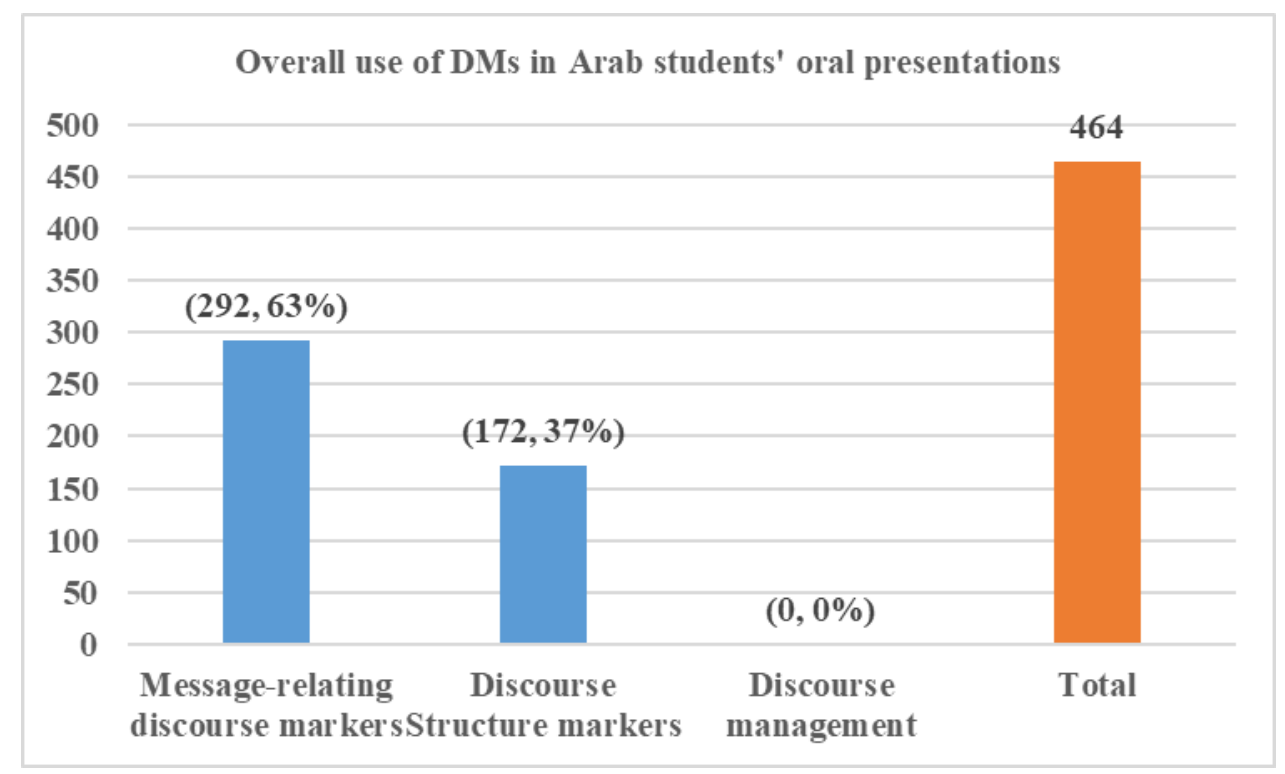

Figure 1. Overall frequencies of DMs used in oral presentations by Arab students

As illustrated in the figure, the Arab students employed two major categories in their oral presentation, the message-related DMs and the discourse structure DMs with the former the most frequently. However, they did not use any discourse marker to manage their oral presentation. In the following sub-sections, the types and functions of each category are reported and discussed.

\subsection{Types and Functions of Message-Relating DMs}

Message-relating DMs operate at the sentence level to create sentence coherence (Fraser, 2009). According to Fraser (1999), the role of these markers is to create cohesive relation by relating the messages in two consequent sentences, S1 and S2. The data analysis (Table 1) showed that DMs realized three types of cohesive relations, namely elaborative, inferential, and contrastive. The elaborative function was the most frequently achieved function.

Table 1. Frequencies and Functions of DMs Used by Arab Students

\begin{tabular}{llllc}
\hline DMs & Cohesive Relation & Functions & Used DMs & $f$ \\
\hline & Addition & and, also, in addition, moreover, is another & 146 \\
\cline { 2 - 5 } & Alteration & or & 26 \\
\hline
\end{tabular}




\begin{tabular}{lllc} 
& Emphasis & in particular, I mean & 27 \\
\hline Exemplar & for example / instance & 16 \\
\hline Similarity & Not used & 0 \\
\hline Conclusion & $\begin{array}{l}\text { so, because of, accordingly, it can be } \\
\text { concluded that, therefore }\end{array}$ & 20 \\
\hline Causality & because & 6 \\
\hline Contrastive & Sequencing & $\begin{array}{l}\text { first of all, first, the first, second, the } \\
\text { second, last, the last one }\end{array}$ & 18 \\
\hline & contrast & but, still, whereas, while & 30
\end{tabular}

\subsubsection{Functions of Elaborative DMs}

Elaborative DMs signal an elaboration in S2 to the information contained in S1 (Fraser, 1999). They follow the formula of $\mathrm{S} 1+($ elaborative $\mathrm{DM})+\mathrm{S} 2$ in which the message in $\mathrm{S} 2$ is parallel to the message in S1. The data analysis showed that the Arab students used the elaborative markers to achieve four types of coherence during their oral presentations: (1) addition, (2) exemplar, (3) emphasis/specifying, and (4) alternation. The addition function was the most frequently achieved function.

Fraser (2009) proposed that the addition function is achieved through the use of markers, such as 'and', 'above all', 'also', 'besides', 'further(more)', 'in addition', 'moreover', etc. These markers signal that the content of S2 is to be taken as an addition to the concept represented by S1. The data analysis showed that four markers were used to serve the addition function, namely 'and', 'also', 'another', and 'moreover'. In Example 1, the Arab student presented about 'clipping process' as a type of abbreviation in communication.

Example 1

$209 \rightarrow$ There is another type of clipping which omits the chief from the word. And,

$210 \rightarrow$ acronyms and non-conventional omission of the apostrophe. And, the

211 students feel that ... the results showed that when they communicate by

212 abbreviation, they do not feel ambiguous when they communicate, they understand what they are typing.

In Example 1, the student used the addition marker 'and' two times. The first use was to add other types of clipping process 'acronyms and non-conventional omission of the apostrophe'. The second use was to add a new idea to the concept represented in the previous sentence that the use of clipping does not affect student's communication or understanding.

Alternation is another function that is achieved through the use of markers, such as 'alternatively', 'or', 'either...or', 'otherwise', or 'rather'. The use of these markers signal that the content of S2 is to be taken as an alternative to the concept represented by $\mathrm{S} 1$ or the 
preceding discourse (Fraser, 2009). In the present study, the Arab students only used ' $o r$ ' and 'either...or' to create sentence coherence by means of alternation. In Example 2, the Arab student presented about the notion of 'frames'.

Example 2

209 Why frame is useful? It is useful in understanding how conversational

$210 \rightarrow$ interactions can either build alignment or signal conflict between interactants.

As illustrated in Example 2, the student elaborated on the functions of frames by providing two alternatives. The first alternative was 'building alignment' and the second one was 'signaling conflict' among interactants. To relate the two functions as alternatives and maintain sentence coherence, the student used the discourse marker 'either...or'.

Another cohesive function achieved by the use of elaborative DMs is the emphasis function. This function is realized through the use of words or phrases such as 'in particular', 'more accurately/ importantly/ precisely/ specifically', 'indeed', 'in fact', or 'I mean' (Fraser, 2009). These markers not only signal a refocus or emphasis on the basic message of the sentence in which they precede, but also they refine the message in the foregoing sentence (Fraser, 2009). These markers follow the formula of S1+ (emphasis DM) + S2 in which the message in S2 signal a general sense of elaboration to the message in $\mathrm{S} 1$. The analysis in this study showed that the use of this type of marker by the Arab students was limited to 'in particular' and ' $I$ mean'. In Example 3, the student's oral presentation involved comparing four journal articles in terms of the study setting.

\section{Example 3}

226 For the similarities and differences of the four articles, the first and two

$227 \rightarrow$ articles were conducted in the Middle East, which is, in particular, Iraq and

228 Jordan. Article three and four were conducted in Malaysia context.

In Example 3, the Arab student reported that the first two articles were conducted in the Middle East in contrast to the second two articles which were conducted in Malaysia. To specify and refine the preceding piece of information, the student used the discourse marker 'in particular'.

Exemplar is the last function realized by the use of elaborative DMs. The use of markers, such as 'for example/instance', 'in other words', or 'that is to say' reflects the relevancy of the current segment of talk (S2) to the foregoing segment (S1) (Fraser, 2009). They are also used by a speaker to illustrate an earlier point as a kind of elaboration. These markers follow the formula of $\mathrm{S} 1+($ exemplar DM) $+\mathrm{S} 2$ in a quasi-parallel relationship. The analysis in this study showed that the Arab students only used 'for example' as an exemplar discourse marker. In Example 4, the student's oral presentation is about the formulation of 'blending' in language.

\section{Example 4}

056 So, moving forward to the other type of linguistic features which is 'blending' 057 which is basically the joining of the first word, the beginning of the word with 


\section{Al Macrothink}

International Journal of Linguistics

ISSN 1948-5425

2022, Vol. 14, No. 1

058 the end of a certain word to create a completely new word with a new meaning

$059 \rightarrow$ (S1). For example 'motel' from motor and hotel and 'brunch' from breakfast and $060 \quad$ lunch which is Malaysian favorite meal, is that right?(S2)

As clearly depicted in Example 4, the student presented about the process of forming a completely new word by blending two different words. To elaborate on this point, the Arab student used the exemplar marker 'For example' at the sentence initial in line 059. The use of this marker was to illustrate the explanation in the previous segment (S1) with relevant examples of blended words, such as 'motel' and 'brunch'.

\subsubsection{Functions of Inferential DMs}

The second category of message-relating DMs identified in the present study was inferential DMs. Based on Fraser (2009), these markers signal that the following assertion is grounded on the foregoing. In other words, these markers signal that the current utterance (S2) conveys a message which is, in some sense, consequential to some aspect of the foregoing (S1). In this case, $\mathrm{S} 1$ forms a basis for the inference in $\mathrm{S} 2$. These markers follow the formula of S1+ (inferential DM) $+\mathrm{S} 2$. The analysis of the Arab students' oral presentations showed that the Arab students used inferential DMs to serve three main types of coherence: (1) conclusion, (2) sequencing, and (3) causality. Conclusion was the most frequently expressed function.

Conclusion is achieved through the use of certain words or phrases, such as 'so', 'as a result', 'because of this/that', 'consequently', 'accordingly', etc. (Fraser, 2009). These markers show that the content of S2 is logical conclusion of the content or condition in S1 (Fraser 1999). In the present study, the findings showed that the Arab students' use of these markers were limited to certain markers, such as 'so', 'because of this/that', 'accordingly', 'it can be concluded that', and 'therefore'. In Example 5, the Arab student presented about instruments for data collection used in a research study.

\section{Example 5}

$141 \quad$ The second article employed quantitative methods to investigate the use of $142143 \rightarrow$ abbreviations in Facebook (S1), so that the researcher construct a questionnaire consisted of 40 abbreviations (S2).

As shown in Example 5, the student used the conclusion marker 'so that' to relate two segments of talk. The first segment (S1) was the type of methods used in the article 'quantitative'. The second segment (S2) was the instrument used for data collection 'questionnaire'. The use of the marker between the two sentences was to infer that the content of S2 is a logical consequence of S1. By the use of this marker, the two sentences were kept coherent as one of them was a reason and the other was a direct result.

Sequencing is another function realized by the use of a number of words or phrases, such as 'after' 'before', 'eventually', 'finally', 'first', 'meanwhile', 'and then', etc. (Fraser, 2009). The data analysis showed that the markers used were 'first', 'the first $X$ ', 'first of all', 'second', 'the second X', 'lastly', 'the last one', and 'and then'. The use of these markers was mainly to set the segments of talk in their chronological sequence. In Example 6, the student presented about 'abbreviation' as a linguistic feature of language. 


\section{Al Macrothink}

International Journal of Linguistics

ISSN 1948-5425

2022, Vol. 14, No. 1

Example 6

039 The first linguistic feature that we are dealing with here is 'abbreviation'

$040 \rightarrow$ which has three sub-categories of linguistic features (S1). First, 'Clipping'

$041 \quad$ which is the process of dropping one syllable in a one or more syllables in a

042 poly-syllabic word (S2).

In this example, the student used the sequencing marker 'first' in line 040 at sentence initial to relate the previous sentence (S1) to the next (S2) in a chronological sequence relationship. The use of this marker helped to maintain coherence by making the student's speech well organized and connected.

Causality is realized by using words or phrases, such as 'since', 'because', 'after all', and 'for this/that reason' (Fraser, 2009). Fraser (2009) explains that these markers are used to signal that S2 provides a reason for the content presented in S1. They are used to relate two segments of talk in a causal relationship. The analysis of the Arab students' oral presentations showed that only the causal markers 'because' and 'as' were employed to create a causal relationship and maintain discourse coherence. Example 7 illustrates the use of 'because'.

Example 7

047 So, basically, the third example here is FL. I think it is kind of not right (S1)

$048 \rightarrow$ because acronyms, basically acronyms deal with the formal setting like NATO

049 and $S P(\mathrm{~S} 2)$.

In $\mathrm{S} 1$, the student thought that ' $F L$ ' cannot be considered as an acronym. To provide a reason that can justify his judgement, the student introduced S2 with the causality marker 'because'. The use of this marker in sentence-medial position helped the student justify his judgement by creating a causal relationship between $\mathrm{S} 1$ and $\mathrm{S} 2$.

\subsubsection{Functions of Contrastive DMs}

Contrastive markers are words or phrases like '(al)though', 'but', 'despite', 'however', 'nevertheless', 'nonetheless', 'while/whereas', etc (Fraser, 2009).. This category of message-relating DMs signals that there is a direct or indirect contrast or disagreement between the content of S1 and the content of S2 (Fraser, 2009). These markers follow the formula of S1+ (contrastive DM) + S2 (Fraser, 1999). The analysis in this study showed that the Arab students used contrastive DMs at fewer frequencies than the elaborative and inferential DMs. In spite of the lengthy list of the contrastive markers in English, the Arab students' uses of these markers were limited to only five markers, namely, 'but', 'still', 'whereas', 'however', and 'while'. Example 8 illustrates a use of this marker. In this example, the student discussed the statement of the problem in his project paper.

\section{Example 8}

Researchers believe that employing code switching in any EFL classroom can affect students negatively since it can prevent students from the use of the target language properly and could make them dependent on their first language. So, this issue has been discussed in previous literature (S1). 
$275 \rightarrow$ However, little is known about Iraqi teachers' perceptions of code switching in

076 an academic context (S2).

As shown in the example, the student introduced the context of the main issue in lines 271-274. He noted that using code-switching in a classroom is a negative practice by a teacher. In line 271 , the student continued to say that this issue has been studied in previous literature. To create a contrastive picture in order to justify the need for conducting his research on code-switching, the student used the contrastive marker 'however' in line 275. The use of this marker signaled that the message entailed in the second discourse segment (S2) contrasted the message in the first segment (S1).

\subsection{Types and Functions of Discourse Structure Markers}

Unlike the message-relating DMS, which achieve coherence at the sentence level, discourse structure markers operate at the whole discourse level to create discourse coherence (Fraser, 1999). The analysis of the oral presentations by the Arab students in this study (Table 2) showed that only two sub-categories of discourse structure markers were employed, namely, attention and topic change markers, with attention markers as the most frequently used. Discourse management markers were not used at all by the Arab students.

Table 2. Frequencies of the Types of Discourse Structure Markers by Arab Students

\begin{tabular}{|c|c|c|c|c|}
\hline DMs & Cohesive Relation & Functions & Used DMs & $f$ \\
\hline \multirow{7}{*}{ 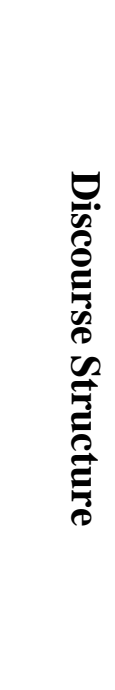 } & Attention & Refocusing & OK, So, Today & 130 \\
\hline & & Signaling topic contrast & alright & 20 \\
\hline & & Signaling surprise & & 0 \\
\hline & Topic change & $\begin{array}{l}\text { Digression (Introducing a new } \\
\text { topic) }\end{array}$ & $\begin{array}{l}\text { for, moving } \\
\text { to/forward, } \\
\text { let's }\end{array}$ & 22 \\
\hline & & Returning to a previous topic & & 0 \\
\hline & & Addition/continuing current topic & & 0 \\
\hline & Discourse Management & Management & & 0 \\
\hline
\end{tabular}

\subsubsection{Functions of Attention DMs}

Attention markers are mainly used at sentence initial position and prior to orientation markers. Such position enables these markers to predict for the orientation of speech and attract the attention to a discourse segment in order to refocus it or to show contrast or surprise (Fraser, 2009). Huddlestone and Fairhurst (2013) suggested that these markers help speakers to transform smoothly from a topic to another and to control the flow of the speech in various ways, such as drawing attention to speaker, indicating turn taking, preparing to speak, and introducing a new topic. Simply speaking, these markers indicate that a change is about to 
take place in the discourse. The analysis of the Arab students' oral presentations showed that these students employed these markers to achieve two functions, (1) signalling contrast and (2) refocusing the topic at hand.

Attention markers that signal contrast, such as 'Alright,', 'Anyway,', 'Anyhow,', 'In any case,', 'In any event,', and 'Well,' indicate that the upcoming discourse activity, which is relevant to some part of the foregoing discourse, carries a contrastive topic (Fraser, 2009). In Example 9, an example is illustrated when the Arab student presented about the notion of 'social frames'.

\section{Example 9}

1122 Frames are social expectations. That's to say, what do you expect from the 1123 conversation? The doctor last time mentioned 'social preference', what one 1124 prefers, right? So if something is unexpected, that means you do not prefer it, 1125 right? It should be for harmony; it should be matching the expectations. $1126 \rightarrow$ Anyway, just an example, look how Neil has an evaluative frame. How do we 1127 know a person is evaluative, or complimenting?

As shown Example 9, the Arab student explained the meaning of 'frame' in lines 1122-1125 as a kind of 'social expectations' or 'preferences'. The student used the attention marker 'anyway' to attract the attention of the listeners to a new piece of discourse regarding frame in the upcoming section of his presentation. The new piece of information relates to one type of frame mentioned in the previous lines. The use of this marker by the student was to create a contrastive piece of talk i.e., a change in current discussion of frame's meaning towards giving examples of such frames. As it can be noticed, the use of the marker by the student was not to digress completely from the current topic to introduce a totally new topic (as in the case of topic-relating markers, explained in the next section), but it was used to introduce a relevant topic on the basis of the immediate forgoing topic.

Another function that can be achieved by attention markers is the refocusing function. This function is achieved through the use of markers, such as 'Look,', 'Now (then), , 'Ok,', 'So,', 'Well (then),' etc (Fraser, 2009). When these markers are used at a sentence initial position, they signal a refocusing on a part of the topic at hand (Fraser, 2009). The analysis in this study showed that 'Ok,', 'So,', 'Today', 'Here' and 'Again,' were used by the Arab students. An illustration is presented in Example 10, where the student presented about the conceptual framework of his project paper.

\section{Example 10}

$891 \rightarrow$ This is the conceptual framework of the study. Here, we have the modifiers as 892 IVs in this study, okay? These modifiers consist of hedges, mitigators, or 893 boosters, so hedge is an IV in this study, mitigator is another IV, booster is $894 \quad$ another IV. So these IVs has their impact in modifying the speech act to express $895 \rightarrow$ politeness, Ok? So, again, here we have the modifiers called IVs, they will be 896 used to affect the type of speech act, or modify the illocutionary force of that 897 speech act to express different types of politeness. 


\section{Macrothink}

The student used a number of refocusing DMs. Each of these markers draw the attention to a part of the topic at hand. The use of 'Here' in line 891 was used to direct the audience to the modifiers of the speech act in his project as IVs (independent variables). The use of ' $S o$,' and 'again,' in line 895 were to attract the attention of the audience and refocus the topic on the 'modifier' mentioned in the previous segment of talk.

\subsubsection{Functions of Topic-Relating (Topic Change) DMs}

Topic-relating DMs is the second sub-category of discourse structure markers. Fraser (2009) provided a list of these markers that include markers, such as 'back (to return) to my original point', 'back to my point, returning to my (previous) point', 'to return to the prior topic', 'if I might return to my prior point,...', 'before I forget', 'that reminds me', 'to conclude', etc. Based on Fraser (2009), these markers can help achieve three main functions, namely to (1) digress from current topic to introduce a new one, (2) return to a previous topic, or (3) continue/add to a new topic. It is worth mentioning that these markers do not show or imply any reference to the messages in previous segments but only used to sequence topics.

In spite of the lengthy list of these markers and the various functions that these markers can achieve in speech, the analysis of the Arab students' use of these markers in their oral presentations showed that only three markers namely 'moving forward', 'for', and 'let's'. Further, these markers were only used to digress from current topic to introduce a new topic. Other functions, such as returning to previous topics, and adding or continuing current topics were not detected in the Arab students' oral presentations. In Example 11, the marker was used by the student to start presenting a new power point slide with a new topic.

Example 11

$063 \rightarrow$ So, moving to the background of the study, Fairclough in 2003 forecasted that 064 technology could have... could have a negative effect on the standard rules of 065 language. This was when there was only 'messenger' application

As shown in the example, the student used the discourse marker 'moving to' to digress from a previous topic to introduce a new topic, which was about the background of the study.

\section{Discussion}

The findings previously reported about the use of DMs by Arab students revealed important facts about the use of these markers in these students' classroom oral presentations. The findings showed that Arab students used two main categories of DMs: the message-relating DMs and discourse structure markers. Message-relating DM was the more frequently used between the two. The use of these markers was helpful for students to maintain sentence and discourse coherence over the three stages of classroom oral presentations (Introduction, Body, and Conclusion). The use of DMs, in fact, reflected the students' linguistic style and attempt to connect their messages and organize their talk.

The use of the message relating markers helped the Arab students to achieve sentence coherence in three ways. First, the students were able to express addition (and, also, in addition, moreover, and is another), give examples (for example/instance), provide emphasis 
(in particular, I mean, indeed, and in fact), show similarity (similarly), and give alternation (or). Second, the students were able to establish contrastive relationship between the messages in their sentences. This was achieved mainly through the use of markers, such as 'but', 'still', 'whereas', and 'while'. Third, the use of certain inferential markers, such as conclusion markers (because of this/that, accordingly, it can be concluded that, and therefore), the causality marker (because), and sequencing markers (first, the first X, first of all, second, the second $X$, last, the last one, and lastly) helped the Arab students provide a basis for inferring their messages. The findings about the use of message-relating discourse markers are in partial agreement with the findings reached by Apraku (2017) who found micro discourse markers, such as 'because' and 'so' achieving consequence effect and the marker 'but' expressing contrastive relationships.

The use of the discourse structure markers, on the other hand, helped the Arab students to achieve discourse coherence in three ways. First, the use of markers, such as 'for', 'moving to I forward', and 'let's' helped the students digress from one topic to another. Second, the use of the marker 'alright' at sentence initial helped the students to signal topic contrast. Third, the use of markers, such as 'Ok', 'So', 'Today', 'Here', and 'Again' helped the students to refocus their topics. These findings confirm the findings reached by Apraku (2017) who found that micro discourse markers, such as 'so', 'now', 'alright', and 'ok' helped open and organize oral presentations, thus performing structural functions in oral presentations.

Over the use of DMs by the Arab students, the following points were also observed:

First, it was noticed that the Arab students did not use other important sub-categories of DMs as proposed in Fraser (1996). Elaborative message-relating DMs that show similarity were not found to be used by Arab students of the present study. The students also did not employ discourse structure markers that attract attention by means of showing surprise and topic change markers that are used to return to a previous topic or add/continue from the current topic. Discourse management markers were also not found to be used. The absence of these markers in the Arab students' oral presentations might signal a shortage in their linguistic repertoire of discourse markers and their lack of awareness of the role of these important markers in rendering an effective oral presentation (Kapranov, 2020; Aziz et al., 2016). Alraddadi (2019) maintained that the absence of discourse markers in oral presentation would not only affect the flow of the ideas, coherence of speech, and organization of facts but it might also alter the real intention of the presenter.

Second, the students used new DMs that were not listed by Fraser (1996) in his taxonomy of DMs. The markers included the addition marker 'is another', emphasis/specifying marker ' $I$ mean', the conclusion marker 'it can be concluded that', the contrastive marker 'while', and the refocusing markers 'today', 'here', and 'again'. These markers were found to be typically used by Arab students during their oral presentations and achieved the same functions proposed by Fraser (1996). As Arab students are not native speakers of English, the use of these expressions as discourse markers can be viewed as a compensation strategy in communication, indicating the students' ability to adapt to a linguistic situation when performing the oral presentation. The use of these markers can be said to reflect discourse 
competence development on the part of Arab students to adapt to new speech events. This finding supports previous findings reached by Akhyak and Anik (2013) who maintained that non-native speakers of the target language can adjust their speaking to suit the communicative situation as an indication of speaking competence. The results by House (2013) also revealed that the students in his study developed the use of certain markers to adapt to new situations indicating a development in their discourse competence of the use of these markers, which helped them accommodate to new communicative situations. Based on these researchers, it can be said that the Arab students of the present study could have used the markers in ways that enabled them to accommodate to new pragmatic and academic situations such as that of the classroom oral presentation.

\section{Conclusion}

This study was conducted to investigate the use of DMs in classroom oral presentation by Arab postgraduate students studying in Malaysian universities. By identifying the types and functions of these markers, the study was able to shed light on how Arab students use these markers in their classroom oral presentation. The absence of important types of DMs in these students' oral presentations might indicate an inadequate linguistic repertoire of DMs on the part of the students. Thus, it would be beneficial for Arab students to improve their vocabulary and awareness about discourse markers so that they do better in academic speech. The study, however, was limited to one faculty of a public university in Malaysia. Extending the scope of the study to include more faculties and other universities in the region will provide deeper insights into DM use by Arab students. It is also recommended to include other social factors, such as students' gender and proficiency level to gain insights into varied uses of DMs. The scope of this study was also limited to the analysis of students' use of DMs at the semantic, syntactic, and pragmatic properties. Considering other linguistic aspects of DMs such as position of DMs in utterances would yield more comprehensive understanding of these markers in classroom oral presentations. Since classroom oral presentation is a main teaching and learning instrument in Malaysian universities, this study recommends that these students receive training on the use of DMs prior to or during their postgraduate studies. This training can be designed to provide these learners with linguistic information on how to employ these markers to render more effective and well-organized oral presentations.

\section{References}

A Alghamdi, N. (2021). Learning to Present in English: Exploring the Voices of Preparatory-Year Female Undergraduates in Saudi Arabia. Arab World English Journal (AWEJ), 12.

Ahmed, W. K., \& Maros, M. (2017). Using Hedges as Relational Work by Arab EFL Students in Student-Supervisor Consultations. GEMA Online ${ }^{\circledR}$ Journal of Language Studies, $17(1)$.

Al-Hawamdeh, R. F., \& Al-Khanji, R. (2017). The Effects of Motivation and Other Factors on Second Language Acquisition: A Case Study on Achieving Advanced Oral Proficiency in English. Arab World English Journal (AWEJ), 8(1), 165-178. 
Al-Sobhi, B. M. S., \& Preece, A. S. (2018). Teaching English speaking skills to the Arab students in the Saudi school in Kuala Lumpur: Problems and solutions. International Journal of Education and Literacy Studies, 6(1), 1-11.

Al Hosni, S. (2014). Speaking difficulties encountered by young EFL learners. International Journal on Studies in English Language and Literature (IJSELL), 2(6), 22-30.

Alamri, H. R., \& Al-Tunisi, N. T. (2019). Writing Proficiency Levels Among Arabic and English Language Student Teachers and their Perceptions of Challenges in Writing Skill.

Alraddadi, B. M. J. (2019). An Analysis of the Effects of Explicit Teaching on the Acquisition of Structural Discourse Markers in EFL Speaking Classes in Saudi Arabia. (PhD), University of Central Lancashire.

Apraku, A. (2017). The use of discourse markers in lecture delivery: A study of two Public Universities in Ghana. (PhD Thesis), University of Education, Winneba.

Arya, T. (2020). Exploring discourse marker use in Thai University students' conversations. LEARN Journal: Language Education and Acquisition Research Network, 13(1), 247-267.

Babanoğlu, M. P. (2014). A Corpus-based Study on the Use of Pragmatic Markers as Speech-like Features in Turkish EFL Learners' Argumentative Essays. Procedia - Social and Behavioral Sciences, 136, 186-193.

Banguis-Bantawig, R. (2019). The role of discourse markers in the speeches of selected Asian Presidents. Heliyon, 5, e01298.

Bianchi, R., \& Razeq, A. H.-A. (2017). The English language teaching situation in Palestine English Language Education Policy in the Middle East and North Africa (pp. 147-169). Springer.

Creswell, J. W. (2012). Educational Research: Planning, Conducting, and Evaluating Quantitative and Qualitative Research (4th ed.). Boston, USA: Pearson Education.

Creswell, J. W. (2013). Research Design: Qualitative, Quantitative, and Mixed Methods Approaches (4th ed.). Boston: Pearson Education, Inc.

Dörnyei, Z. (2007). Research Methods in Applied Linguistics: Quantitative, Qualitative, and Mixed Methodologies. Oxford University Press.

Elza, M. (2020). Higher Intermediate Students' Discourse Competence in Presenting Final Project. Paper presented at the 1st International Conference on Lifelong Learning and Education for Sustainability (ICLLES 2019).

Fernández-Polo, F. J. (2014). The role of I mean in conference presentations by ELF speakers. English for Specific Purposes, 34(1), 58-67.

Fernández, J., Gates Tapia, A., \& Lu, X. (2014). Oral proficiency and pragmatic marker use in L2 spoken Spanish: The case of pues and bueno. Journal of Pragmatics, 74, 150-164.

Fortuno, B. (2006). Discourse markers within the university genre: A contrastive study between Spanish and North American lectures. $\mathrm{PhD}$ Dissertation. English Studies Department, Humanities and Social Sciences Faculty, Universitat Jaume.

Fraser, B. (1999). What are discourse markers? Journal of pragmatics, 31(7), 931-952. 


\section{Ml Macrothink}

International Journal of Linguistics

ISSN 1948-5425

2022, Vol. 14, No. 1

Fraser, B. (2009). An account of discourse markers. International Review of Pragmatics, 1(2), 293-320.

Furkó, P., Kertész, A., \& Abuczki, Á. (2019). Discourse markers in different types of reporting Indirect Reports and Pragmatics in the World Languages (pp. 243-276). Springer.

Galaczi, E. D. (2013). Interactional Competence across Proficiency Levels: How do Learners Manage Interaction in Paired Speaking Tests?. Applied linguistics, 5(2014), 553-574.

Halliday, M. A., \& Hasan, R. (1976). Cohesion in English. London: Longman.

Hincks, R. (2010). Speaking rate and information content in English lingua franca oral presentations. English for Specific Purposes, 29(1), 4-18.

Huddlestone, K., \& Fairhurst, M. (2013). The pragmatic markers anyway, okay, and shame: A South African English corpus study. Stellenbosch Papers in Linguistics Plus, 42(1), 93-110.

Hum, M., Trihartanti, R. P., Hum, M., \& Damayanti, D. (2014). The Use of 'Oh'and 'Well'as Discourse Markers in Conversation of Bandung State Polytechnic Students. LEARN Journal: Language Education and Acquisition Research Network, 7(1), 22-44.

Khan, M. S., \& Salam, A. R. (2019). Oral Communication Barriers Facing Arab Medical Students. Indian Journal of Public Health Research \& Development, 10(6).

Lin, C.-Y. (2010). '... that's actually sort of you know trying to get consultants in...': Functions and multifunctionality of modifiers in academic lectures. Journal of Pragmatics, 42(5), 1173-1183.

Miima, F., Ondigi, D. S., \& Mavisi, R. (2013). Teachers' pertception about integration of ICT in teaching and learning of Kiswahili language in secondary schools in Kenya. International Journal of Arts and Commerce, 2(3), 27-32.

Moghaddasi, M. E., Bavali, M., \& Behjat, F. (2020). How Does Explicit and Implicit Instruction of Formal Meta-discourse Markers Affect Learners' Oral Proficiency?. International Journal of Foreign Language Teaching and Research, 8(33), 99-113.

Morell, T. (2015). International conference paper presentations: A multimodal analysis to determine effectiveness. English for Specific Purposes, 37, 137-150.

Namaziandost, E., Neisi, L., Kheryadi, \& Nasri, M. (2019). Enhancing oral proficiency through cooperative learning among intermediate EFL learners: English learning motivation in focus. Cogent Education, 6(1), 1-15.

Nattinger, J. R., \& DeCarrico, J. S. (1992). Lexical phrases and language teaching. Oxford University Press.

O'Boyle, A. (2014). 'You' and 'I' in university seminars and spoken learner discourse. Journal of English for Academic Purposes, 16(1), 40-56.

Pourfarhad, M., Azmey, F. L. A., \& Hassani, L. (2012). Perceptions of International Students on Academic Literacy Focusing on Speaking and Listening Skills in Malaysia. Procedia Social and Behavioral Sciences, 69, 197-205. 


\section{Macrothink}

International Journal of Linguistics

ISSN 1948-5425

2022, Vol. 14, No. 1

Rezaee, M., Aghagolzadeh, F., \& Birjandi, P. (2014). The effect of lecturers' gender on the use of discourse markers. International Journal of Research Studies in Language Learning, $4(2), 69-87$.

Saputri, R. E. G., \& Fitriati, S. W. (2019). Students' Discourse Markers in In-Class Oral Presentations (A Case of English Language Education Students at a University. UNNES-TEFLIN National Seminar, 3(1), 101-105.

Schiffrin, D. (1987). Discourse markers. Cambridge University Press.

Schiffrin, D. (1988). Discourse markers. Cambridge University Press.

Schleef, E. (2009). A cross-cultural comparison of the functions and sociolinguistic distribution of English and German tag questions and discourse markers in academic speech. Cross-linguistic and cross-cultural perspectives on academic discourse (Vol. 193, pp. 61-79). Amsterdam / Philadelphia: John Benjamins B.V.

Wei, M. (2011). A comparative study of the oral proficiency of Chinese learners of English across task functions: A discourse marker perspective. Foreign Language Annals, 44(4), 674-691.

Yakubu, M. S. (2013). An analysis of discourse markers in academic report writing: pedagogical implications. International Journal of Academic Research and Reflection, 1(3), $15-24$.

Yang, F.-Y., Chang, C.-Y., Chien, W.-R., Chien, Y.-T., \& Tseng, Y.-H. (2013). Tracking learners' visual attention during a multimedia presentation in a real classroom. Computers \& Education, 62, 208-220.

Young, R. (2008). Using technology tools in the public school classroom. Master Thesis. University of Wisconsin.

Yulita, E., Rukmini, D., \& Widhiyanto, W. (2021). Comparison of the use of discourse markers in English speeches between non-native and native speakers of English. English Education Journal, 11(22), 198-207.

Živković, S. (2015). Introducing students to the genre of presentations for professional purposes. Mediterranean Journal of Social Sciences, 6(2 S2), 201.

\section{Copyrights}

Copyright for this article is retained by the author(s), with first publication rights granted to the journal.

This is an open-access article distributed under the terms and conditions of the Creative Commons Attribution license (http://creativecommons.org/licenses/by/4.0/) 